\title{
Rust roest
}

Citation for published version (APA):

Westerterp, K. R. (2001). Rust roest. Universiteit Maastricht. https://doi.org/10.26481/spe.20010928kw

Document status and date:

Published: 28/09/2001

DOI:

$10.26481 /$ spe.20010928kw

Document Version:

Publisher's PDF, also known as Version of record

\section{Please check the document version of this publication:}

- A submitted manuscript is the version of the article upon submission and before peer-review. There can be important differences between the submitted version and the official published version of record.

People interested in the research are advised to contact the author for the final version of the publication, or visit the DOI to the publisher's website.

- The final author version and the galley proof are versions of the publication after peer review.

- The final published version features the final layout of the paper including the volume, issue and page numbers.

Link to publication

\footnotetext{
General rights rights.

- You may freely distribute the URL identifying the publication in the public portal. please follow below link for the End User Agreement:

www.umlib.nl/taverne-license

Take down policy

If you believe that this document breaches copyright please contact us at:

repository@maastrichtuniversity.nl

providing details and we will investigate your claim.
}

Copyright and moral rights for the publications made accessible in the public portal are retained by the authors and/or other copyright owners and it is a condition of accessing publications that users recognise and abide by the legal requirements associated with these

- Users may download and print one copy of any publication from the public portal for the purpose of private study or research.

- You may not further distribute the material or use it for any profit-making activity or commercial gain

If the publication is distributed under the terms of Article $25 \mathrm{fa}$ of the Dutch Copyright Act, indicated by the "Taverne" license above, 
066 


\section{$m G$ \\ vac \\ 538}

\section{RUST ROEST}

Rede uitgesproken bij de aanvaarding van het ambt van bijzonder hoogleraar in de Humane Energetica aan de Universiteit Maastricht op vrijdag 28

september 2001

door

Dr. K.R. Westerterp 
PPN. 244) 83101

Universisistsibiliotheek

Universitetit Mastrich 
Mijnheer de Rector Magnificus, Leden van het College van Bestuur van de Universiteit Maastricht, collega's, familie, vrienden, belangstellenden.

De meeste volwassen dieren, waaronder de mens, handhaven een energiebalans die tot uiting komt in een min of meer constant lichaamsgewicht. Het gewicht vertoont op jaarbasis een verandering die meestal kleiner is dan $1 \mathrm{~kg}$ oftewel de energieinname verschilt op jaarbasis niet meer dan $30 \mathrm{MJ}$, dat is een hoeveeelheid energie die men in ongeveer 3 dagen inneemt, van het energiegebruik. Dit betekent dat er op jaarbasis een nauwkeurige afstemming is van de energie-inname op het energiegebruik en gelijktijdig dat er een effect is van energie-inname op gebruik. Een gemiddelde volwassene consumeert en gebruikt op jaarbasis 3000 tot $6000 \mathrm{MJ}$, afhankelijk van lichaamsgrootte en lichamelijke activiteit. De discrepantie van $30 \mathrm{MJ}$ op jaarbasis betekent een afwijking van 0.5 tot $1 \%$ tussen energiegebruik en energie-inname. Variatie in het energiegebruik is vooral een functie van lichamelijke activiteit met als effect parameter gezondheid, onder andere weerspiegeld - in de energiebalans en het lichaamsgewicht. Dit resulteert in adviezen over een zogenoemde 'gezonde' lichamelijke activiteit en in de conclusie: rust roest. 


\section{Methode}

Onderzoek naar lichamelijke activiteit, energiebalans en gezondheid heeft recentelijk tot veel nieuwe inzichten geleid dankzij de ontwikkelingen van technieken voor het meten van het energiegebruik en lichaamsbeweging onder dagelijkse leefomstandigheden. Tot 15 jaar geleden werd de dagelijkse energiebehoefte van een individu gebaseerd op de gerapporteerde voedselinname. Sinds de introductie van de tweevoudig gemerkt water methode voor het meten van het totaal energiegebruik gebruiken we een objectieve referentiemethode voor het bepalen van de energiebehoefte. De methode is doorgedrongen tot de hoogste adviesorganen zoals de wereld gezondheids organisatie (WHO). Het energiegebruik voor lichamelijke activiteit is de belangrijkste variabele in het dagelijks energiegebruik. Een meting van het totaal energiegebruik, gecombineerd met een meting van het energiegebruik in rust geeft een nauwkeurige maat voor het activiteitsniveau van een individu in de vorm van de zogenoemde activiteitsindex. De activiteitsindex is het totaal energiegebruik, gedeeld door het energiegebruik in rust. Bepaling van het totaal energiegebruik kent de volgende procedure. Proefpersonen drinken 's -avonds een flesje water, verrijkt met zware zuurstof en zware waterstof, stabiele isotopen die ook van nature in ons lichaam voorkomen, na het verzamelen van een urinemonster voor het meten van de achtergrondconcentratie van beide isotopen. 


\section{Rust roest}

Vervolgens wordt een urinemonster genomen op de ochtend na dosering, wanneer volledige menging met het lichaamswater heeft plaatsgevonden en op enkele momenten daarna, teneinde de verdwijningssnelheid van de isotopen uit het lichaam te meten. De verdwijning van zware zuurstof is een functie van de koolstofdioxide productie en van het waterverlies terwijl zware waterstof alleen met water het lichaam verlaat. De verdwijningssnelheid van zware zuurstof, verminderd met de verdwijningssnelheid van zware waterstof, is daarme een maat voor de koolstofdioxide productie. Hieruit wordt, met informatie over de koolhydraat-, eiwit- en vetverhouding van het verbrandingssubstraat, het energiegebruik berekend. De methode blijkt nauwkeurig te zijn en is niet belastend voor de proefpersoon. De methode wordt toegepast voor het meten van het energiegebruik van voortijdig geboren kinderen, patienten waarvan men de energiebehoefte wil bepalen, allerlei categorieën mensen in het dagelijks leven van jong tot oud en bij evaluatie van activiteitsinterventies inclusief sport.

Tweevoudig gemerkt water wordt toegepast voor het meten van de energiebehoefte en de activiteitsindex over een interval van één week voor bijvoorbeeld een pas geboren kind of een duuratleet met een extreem hoog energiegebruik tot drie weken voor een bedlegerige patient of een hoogbejaard individu. Dit is één tot drie maal de biologische halfwaarde tijd, oftewel de tijd waarover het gehalte van de gebruikte stabiele isotopen in het lichaam halveert. 


\section{Humane energetica}

Om inzicht te krijgen in variatie in het energiegebruik en de lichamelijke activiteit over kortere intervallen, hebben we een versnellingsopnemer ontworpen die registratie van lichaamsbeweging mogelijk maakt in voorwaartse, zijwaartse en opwaartse richting. Met hulp van de industrie heeft dit recentelijk geresulteerd in een opnemer ter grootte van een luciferdoosje die aan een band om het middel wordt gedragen en over meerdere weken van minuut tot minuut lichaamsbeweging vastlegt in een electronisch geheugen. Gelijktijdige toepassing van tweevoudig gemerkt water en registratie van lichaamsbeweging met de versnellingsopnemer geeft inzicht in het totale energiegebruik en het dagelijks activiteitspatroon, wat mogelijkheden voor interpretatie van interventies en objectieve evaluaties geeft. Resultaten van onderzoek en daaruit voortvloeiende nieuwe onderzoeksvragen wil ik toelichten op basis van enkele gegevens verzameld in de afgelopen 15 jaar. 


\section{Resultaten}

Dagelijkse lichamelijke activiteit en energiegebruik De activiteitsindex varieert binnen nauwe grenzen. In 1985 definieerde de WHO een waarde van 1.5 voor iemand met een 'zittend' bestaan en een waarde van 2.1 voor iemand met een beroep met zware lichamelijke inspanning. $\mathrm{Bij}$ een activiteitsindex van 1.5 wordt $23 \%$ van het dagelijks energiegebruik besteed aan lichamelijke activiteit, bij een activiteitsindex van 2.1 is dit $42 \%$. Op dit moment wordt door dezelfde instantie gewerkt aan een actualisatie van deze getallen op basis van voor een aanzienlijk deel door ons geleverde gegevens van het energiegebruik gemeten met tweevoudig gemerkt water. De gemiddelde waarde van de activiteitsindex, gemeten met tweevoudig gemerkt water, blijkt in Nederland 1.7 te zijn, oftewel de gemiddelde Nederlander besteedt ongeveer $1 / 3$ van het dagelijks energiegebruik an lichamelijke activiteit. Mensen die één of meerdere dagen in onze respiratiekamer verblijven, een kleine hotelkamer, zonder bewegingsapparatuur, hebben een activiteitsindex van 1.3 to 1.5 . Dat is dus een waarde voor de ondergrens bij een extreem zittend bestaan. Ongetrainde mensen die worden onderworpen aan een intensief inspanningsprogramma van een week of langer, zoals militairen in een trainingskamp, bereiken een waarde van 2.0 tot 2.5 . De waarde van 2.0 tot 2.5 lijkt een bovengrens te zijn voor de meeste mensen. Wanneer men deze waarde overschrijdt is het 
nauwelijks mogelijk om voldoende te eten om een energiebalans te bereiken en om het aanwezige prestatieniveau te handhaven op de langere termijn. Een uitzondering hierop vormen professionele duuratleten. Een van onze eerste studies toonde aan dat wielrenners tijdens de 'Tour de France' over drie weken een gemiddelde activiteitsindex van 4 tot 5 bereiken zonder verlies van lichaamsgewicht. Hierbij dienen we ons echter te realiseren dat professionele wielrenners mensen zijn met een specifieke aanleg, die jarenlang intensief hebben getraind en, om tijdens de rit aan hun energiebehoefte te voldoen, gebruik maken van voedingssupplementen. Ter vergelijking, bij vrij levende vogels en kleine zoogdieren is een maximale waarde van het totale energiegebruik van 4 tot 7 maal het rustgebruik waargenomen met een tendens tot lagere waardes bij toenemende lichaamsgrootte. De waarde van 4 tot 5 maal het onderhoudsgebruik zoals waargenomen bij wielrenners tijdens de 'Tour de France' lijkt hiermee in overeenstemming. De minimumwaarde van de activiteitsindex bij mensen is dus 1.3-1.5, het populatiegemiddelde 1.7 en de maximumwaarde normaliter 2.0-2.5, met uitschieters tot $5 \mathrm{bij}$ professionele duursporters. Wat bepaalt nu de variatie in energiegebruik tussen individuen en welke konsekwenties heeft dit voor de gezondheid.

Een optimaal lichaansgewicht

$\mathrm{Er}$ is een duidelijke relatie tussen lichaamsgewicht, lichaamssamenstelling en energiegebruik. Mensen 
die zwaar zijn gebruiken meer energie dan mensen die licht zijn. Dit komt zowel door een hoger energiegebruik in rust oftewel het onderhoudsgebruik als door een verschil in de andere componenten van het energiegebruik. Een vrouw van $60 \mathrm{~kg}$ gebruikt voor onderhoud $6 \mathrm{MJ} / \mathrm{dag}$ en in totaal $10 \mathrm{MJ} / \mathrm{dag}$. Deze getallen zijn bij een lichaamsgewicht van $90 \mathrm{~kg}$ gemiddeld $7 \mathrm{MJ} / \mathrm{dag}$ en $12 \mathrm{MJ} / \mathrm{dag}$. Mannen hebben bij een bepaald gewicht meer actieve celmassa en minder lichaamsvet. $Z o$ is het gemiddelde energiegebruik van een man van 60 $\mathrm{kg}$ ongeveer gelijk aan dat van een vrouw van $90 \mathrm{~kg}$. In het algemeen geldt dat hoe zwaarder een vrouw of man is hoe hoger het energiegebruik en dus ook hoe hoger de energie-inname. Een hoger lichaamsgewicht resulteert in een hoger onderhoudsgebruik en gemiddeld ook in een hoger gebruik voor lichamelijke activiteit. Wel blijken mensen met overgewicht, ondanks het verschijnsel dat zij hun energiegebruik voor lichamelijke activiteit enigzins blijken te verhogen, niet dezelfde hoeveelheid activiteit te verrichten als mensen met een lager gewicht. Dit geldt met name voor activiteiten die gepaard gaan met lichaamsverplaatsing zoals lopen. Mensen met bijvoorbeeld een twee keer zo groot lichaamsgewicht blijken hun energiegebruik voor lichamelijke activiteit niet te verdubbelen, wat echter wel nodig zou zijn om dezelfde afstand te lopen. In werkelijkheid verhogen $\mathrm{zij}$ het activiteitsgebruik met ongeveer slechts 20\%. Mensen met ondergewicht zoals bijvoorbeeld mensen met anorexia nervosa 


\section{Humane energetica}

Sportactiviteiten leiden wel tot een hogere activiteitsindex wanneer er sprake is van duurtraining met een hoge intensiteit. Zo bleek in een bepaalde studie de activiteitsindex sterk omhoog te gaan tijdens een intensieve looptraining. Mensen met een zittend bestaan en zonder ervaring met hardlopen werden getraind en liepen na bijna een jaar daadwerkelijk een halve marathon. De activiteitsindex nam toe van een aanvangswaarde van gemiddeld 1.6 tot een waarde van 2.1. De waarde van 2.1 werd verrassend genoeg al bereikt na 8 weken training en bleef hetzelfde gedurende de verdere trainingsperiode ondanks een verdubbeling van het trainingsvolume. $\mathrm{Na} 8$ weken werd ongeveer $25 \mathrm{~km}$ per week afgelegd tijdens de looptrainingen en aan het eind was dit ongeveer $50 \mathrm{~km}$ per week. De niet-trainingsactiviteit, zoals waargenomen met versnellingsopnemers, veranderde niet tijdens de trainingsperiode dus de verandering van de activiteitsindex kon volledig worden toegeschreven aan de training zelf. Dit betekent dat het energiegebruik voor een bepaalde activiteit door training wordt gereduceerd. Deze toename van de efficientie van een activiteit door herhaalde uitvoering is uiteraard van belang voor het prestatievermogen. Met dezelfde hoeveelheid energie kan, in het geval van looptraining, een grotere afstand worden afgelegd. In een situatie waarbij met activiteit een verhoging van het energiegebruik wordt nagestreeefd, bijvoorbeeld om een negatieve energiebalans te creëren bij overgewicht, zal dit juist als een nadeel worden 


\section{Rust roest}

ervaren. De looptraining bleek voorts minder geschikt te zijn voor mensen met overgewicht. Van de 32 personen die begonnen met de training waren er 9 die voortijdig stopten. Alle uitvallers hadden een lichaamsgewicht dat hoger was dan de doorzetters, maar er was zeker geen sprake van overgewicht. Activiteiten met een hoge intensiteit zoals hardlopen blijken dus niet geschikt te zijn voor mensen met een hoger lichaamsgewicht. Rustig lopen is voor hen een activiteit die veel langer kan worden volgehouden om zo een hogere activiteitsindex te bereiken.

Lichamelijke activiteit, lichaamssamenstelling en energiebalans

Een verandering van lichamelijke activiteit resulteert in een verandering van het energiegebruik. Er ontstaat vervolgens een nieuwe energiebalans door een geleidelijke aanpassing van de energie-inname. Het omgekeerde is ook het geval, namelijk een verandering van de energie-inname heeft een verandering van het energiegebruik tot gevolg. De aanpassing van inname aan gebruik en het effect van inname op gebruik is onvolledig, maar kleine veranderingen in de energiebalans hebben op de lange duur grote gevolgen voor de lichaamssamenstelling. Het besluit om dagelijks per auto naar het werk te gaan inplaats van een afstand van bijvoorbeeld $5 \mathrm{~km}$ per fiets af te leggen resulteert in een verandering van het energiegebruik van $600-700 \mathrm{~kJ}$ per dag. Wanneer de energie-inname zich niet zou aanpassen aan het veranderde gebruik 
zou dit resulteren in een gewichtstoename van meer dan $4 \mathrm{~kg}$ over een jaar. Omgekeerd resulteert dit bij de overstap van de auto naar de fiets voor de gemiddelde volwassene in een gewichtsverlies van bijna $4 \mathrm{~kg}$ over een jaar, wanneer de energie-inname hetzelfde blijft.

De toename van de incidentie van overgewicht wordt vaak geweten aan een afname van de dagelijkse lichamelijke activiteit. De andere verklaring is een toename van de energie-inname ten gevolge van het overvloedige voedselaanbod. Een eenduidig antwoord valt niet te geven gezien de geringe grootte van een discrepantie tussen beide parameters die op termijn leidt tot overgewicht en de nauwkeurigheid waarmee energie-inname is te meten en. Het is wel duidelijk dat overgewicht makkelijk kan ontstaan door een toename van de energie-inname en dat deze niet eenvoudig kan worden gecompenseerd door een toename van het energiegebruik. Tijdens een maaltijd is een energieinname van $200 \mathrm{~kJ} / \mathrm{min}$ niet ongebruikelijk. Bij een intensieve activiteit zoals hardlopen bedraagt het energiegebruik 'slechts' $40-50 \mathrm{~kJ} / \mathrm{min}$. Met het overvloedige voedselaanbod op veel plaatsen in de huidige samenleving is het risico van teveel eten hiermee groot. Gewichtsverlies bij overgewicht blijkt in de praktijk ook alleen maar op te treden door een vermindering van de energie-inname. Theoretisch zou bij mensen met overgewicht een verhoging van de lichamelijke activiteit eveneens moeten kunnen leiden tot gewichtsverlies maar dat blijkt in de praktijk zelden het geval te zijn. 
Een veel geadviseerde behandeling van overgewicht is een energiebeperkt dieet in combinatie met een trainingsprogramma ter verhoging van het energiegebruik. Combinatie van de resultaten van de vele vergelijkende studies naar het gewichtsverlies bij het volgen van een dieet met of zonder een trainingsprogramma ter verhoging van het energiegebruik leidt tot de verrassende conclusie dat het effect op lichaamsgewicht en lichaamssamenstelling hetzelfde is. Ook hier geeft de tweevoudig gemerkt water methode voor het meten van het totaal energiegebruik de verklaring. Het energiegebruik van mensen op een dieet in combinatie met een trainingsprogramma is hetzelfde als dat van degene op hetzelfde dieet zonder een trainingsprogramma. Het extra energiegebruik tijdens de training wordt waarschijnlijk gecompenseerd door een reductie van lichamelijke activiteit in de niet-trainingstijd. Gelijktijdige waarneming van het activiteitspatroon met versnellingsopnemers zou dit kunnen bevestigen maar dit is nog niet gedaan. De compensatie lijkt vooral op te treden in een situatie van een negatieve energiebalans zoals bij het volgen van een energiebeperkt dieet.

Verhoging van de activiteitsindex heeft zeker positieve effecten op het lichaamsgewicht en de lichaamssamenstelling voor hen die inactief zijn. Mensen met een hogere activiteitsindex blijken meer succes te hebben bij het handhaven van gewichtsverlies na een dieetperiode. Ook blijkt er een relatie te zijn tussen de activiteitsindex en de 
lichaamssamenstelling. Bij mannen gaat een hogere activiteitsindex samen met een lager vetgehalte van het lichaam. Bij vrouwen blijkt een hogere lichamelijke activiteit samen te gaan met een hogere vet-vrije massa. Zowel een lagere relatieve vetmassa als een hogere vet-vrije massa zijn positieve indicatoren voor een gezond bestaan in onze Westerse samenleving.

Energiebalans en ziekte

Veel ziektes gaan gepaard met gewichtsverlies oftewel een verstoring van de energiebalans. Een veelgestelde vraag is vervolgens of de verstoring van de energiebalans het gevolg is van een verhoging van het energiegebruik of van een verlaging van de energie-inname. Met de tweevoudig gemerkt water methode voor het meten van het dagelijks energiegebruik is in somige gevallen een eenduidig antwoord gegeven op de vraag of de energiebehoefte is veranderd, zoals bij een aantal chronische aandoeningen te weten HIV-infectie, kanker en ouderdomsaandoeningen zoals Parkinson en Alzheimer.

Het energiegebruik, en daarmee de energiebehoefte, is bij veel aandoeningen verlaagd, in tegenstelling tot de algemene verwachting. In sommige onderzoeken is tevens een meting gedaan van het energiegebruik voor onderhoud zodat dan vervolgens ook het energiegebruik voor lichamelijke activiteit kan worden berekend. Ziekte leidt vaak tot een verhoging van de onderhoudscomponent van het energiegebruik, voorbeelden zijn HIV-infectie en 


\section{Rust roest}

kleincellig longcarcinoom. Dit is opvallend omdat door de ziekte de energie-inname soms verlaagd is en een verlaging van de energie-inname leidt normaliter tot een verlaging van het onderhoudsgebruik. Kennelijk wordt deze verlaging meer dan gecompenseerd door de verhoging door het ziekteproces. Het feit dat de totale energiebehoefte bij de genoemde aandoening niet is verhoogd ondanks een verhoogde energiebehoefte van het lichaam voor onderhoud in deze situatie duidt op een verlaagde lichamelijke activiteit. Patienten zijn weliswaar niet bedlegerig maar de ziekte resulteert wel in bewegingsbeperking door een snelle vermoeidheid.

Theoretisch is de aangewezen interventie voor het herstel van de energiebalans een voedingsinterventie. Gezien de beperkte belastbaarheid van het lichaam in deze situatie zal een verhoging van de voedselinname vaak als een grote belasting worden ervaren door de daarmee gepaard gaande verhoging van het energiegebruik voor de voedselverwerking. Uit energetisch oogpunt lijkt het dan aangewezen om bij chronische ziekte de energiebehoefte voor lichamelijke activiteit te beperken door het vermijden van langdurige inspanning.

Lichamelijke activiteit en veroudering

Veroudering gaat gepaard met een sterke reductie van de energiebehoefte. Uit analyse van beschikbare getallen van het totale energiegebruik van gezonde personen in een leeftijdsbereik van 20 tot 90 jaar 
blijkt een gemiddelde afname van $50 \%$ oftwel een halvering van de energiebehoefte. De afname komt tot stand door een verandering van alle componenten van het energiegebruik. De onderhoudsbehoefte neemt af door een verkleining van de actieve celmassa van het lichaam. Organen worden kleiner met een toename van de leeftijd, inclusief de spieren als grootste orgaanmassa. Deze verandering treedt op zonder noodzakelijkerwijze te resulteren in gewichtsverlies doordat gelijktijdig veelal een vergelijkbare of zelfs grotere toename van de vetmassa plaatsvindt. Daarnaast is er een afname van het energiegebruik door verminderde lichamelijke activiteit.

De gemiddeld lagere lichamelijke activiteit van ouderen in vergelijking met jongeren is mogelijk het gevolg of juist de oorzaak van de afname van de actieve celmassa, waaronder de spiermassa, met toenemende leeftijd. Actieve ouderen blijken echter niet 'gespierder' te zijn dan ouderen met een lager activiteitsniveau. Wel is het zo dat de spierfunctie van actieve ouderen beter is. Door activiteitstraining op latere leeftijd wordt ook vooral de spierfunctie positief beïnvloed en is er weinig effect op de spiermassa. Actieve ouderen hebben een betere spiercoördinatie waardoor zij een geringer risico hebben op vallen en zich langer zelfstandig kunnen redden.

-Een hogere lichamelijke activiteit tot op latere leeftijd blijkt ook samen te gaan met een verbeterde afweer tegen zuurstofradicalen, reactieve zuurstofdeeltjes die schade in het lichaam kunnen 
veroorzaken. Eén van de theorieën over veroudering is een geleidelijke beschadiging van weefsels en cellen door zuurstofradicalen. Er bestaan een aantal systemen in het lichaam om deze zuurstofradicalen op te ruimen en het lijkt er op dat deze systemen beter functioneren bij ouderen die een hoger activiteitsniveau hebben. Helaas is ook gebleken dat men hiervoor waarschijnlijk een doorgaans actieve leefwijze moet hebben en dat bijvoorbeeld kortere, wekelijkse trainingen op latere leeftijd onvoldoende zijn om dit systeem te activeren.

Kortom: rust roest. 


\section{Dankwoord}

De Stichting Wetenschapsbeoefening Universiteit Maastricht maakte mijn bijzonder hoogleraarschap mogelijk, op voordracht van het College van Bestuur en het Bestuur van de Faculteit Gezondheidswetenshappen van de Universiteit Maastricht. De laatste gaf hieraan de vorm van een profileringsleerstoel 'Humane Energetica' op voordracht van het onderzoekinstituut NUTRIM.

Mijn eerste schreden in het wetenschappelijk onderzoek zette ik tijdens mijn biologiestudie onder leiding van wijlen Dr Huub Kluyver. Prof dr Rudi Drent stimuleerde mij vervolgens tot publicatie van de resultaten. Prof dr Anton Steffens gaf mij de mogelijkheid tot het uitvoeren van een promotieonderzoek. Vooral de gelegenheid om hierbij een grote eigen inbreng te hebben heb ik zeer gewaardeerd. Met prof dr Leen de Ruiter en prof dr ir Aren van Es, mijn promotoren, discussieerden we over de analyse en interpretatie van de onderzoeksgegevens. Met een aanbeveling van prof dr Rudi Drent kwam ik in Schotland onder leiding van prof $\mathrm{dr}$ David Bryant in aanraking met de tweevoudig gemerkt water methode voor het meten van het energiegebruik. Het was uiteindelijk wijlen prof dr Foppe ten Hoor die mij in de gelegenheid . stelde om met deze nieuwe methodiek onderzoek te gaan doen bij mensen, als lid van de capaciteitsgroep Humane Biologie van de Universiteit Maastricht. 
De capaciteitsgroep Humane Biologie stelde mij in staat het onderzoek in de 'Humane Energetica' uit te bouwen. Twee personen, Paul Schoffelen en Loek Wouters, waren en zijn hierbij voor mij belangrijke sleutelfiguren. Aan het thuisfront was er de bijdrage aan en de afleiding van de wetenschap van Marit, Arjen en Margriet.

Ik heb gezegd. 